\title{
The influence of mechanical activation on structural evolution of nanocrystalline $\mathrm{SrTiO}_{3}$ powders
}

\author{
Jelena Živojinović a, *, Vera P. Pavlović ${ }^{\mathrm{b}}$, Darko Kosanović a , Smilja Marković ${ }^{\mathrm{a}}$, \\ Jugoslav Krstić ${ }^{c}$, Vladimir A. Blagojević ${ }^{a}$, Vladimir B. Pavlović ${ }^{a}$ \\ ${ }^{a}$ Institute of Technical Sciences of the Serbian Academy of Sciences and Arts, Knez Mihailova 35/IV, 11000 Belgrade, Serbia \\ ${ }^{\mathrm{b}}$ Faculty of Mechanical Engineering, University of Belgrade, Kraljice Marije 16, 11120 Belgrade, Serbia \\ c Institute of Chemistry, Technology and Metallurgy, Department of Catalysis and Chemical Engineering, University of Belgrade, Njegoseva 12, 11000 \\ Belgrade, Serbia; Labs: Faculty of Chemistry, Studentski trg 12-16, III floor, Room 606, Serbia
}

\section{A R T I C L E I N F O}

\section{Article history:}

Received 22 July 2016

Received in revised form

30 September 2016

Accepted 16 October 2016

Available online 17 October 2016

\section{Keywords:}

Mechanical activation

$\mathrm{SrTiO}_{3}$

Microstructure

Ball milling

Size dependence

\begin{abstract}
A B S T R A C T
Structural changes caused by mechanical activation of $\mathrm{SrTiO}_{3}$ powders were investigated using a variety of methods. Average crystallite size continuously decreased with increased activation time to around $20 \mathrm{~nm}$ after $120 \mathrm{~min}$ activation, while mesopore volume and specific surface area increased accordingly. Higher activation times lead to increased agglomeration of nanoparticles to form agglomerates of around $2 \mu \mathrm{m}$ in size, ultimately producing a relatively stable powder, which exhibits lower microstrain than powders activated for shorter periods of time. Raman spectroscopy shows that the behavior of $\mathrm{TO}_{2}$ and $\mathrm{TO}_{4}$ modes is consistent with a decrease in particle size, while behavior of the nonpolar $\mathrm{TO}_{3}$ mode is markedly different, indicating relaxation of the inversion symmetry in polycrystalline $\mathrm{SrTiO}_{3}$. UV-VIS spectra show that mechanical activation has negligible effect on $\mathrm{SrTiO}_{3}$, with a slight shift caused by $\mathrm{TiO}_{2}$ contamination due to presence of air. Other than this, the mechanical activation process preserves the chemical purity of the initial powder.
\end{abstract}

() 2016 Elsevier B.V. All rights reserved.

\section{Introduction}

Materials based on strontium titanate can be found in a variety of applications, like sensors [1], catalysis [2], UV detectors [3], solar cell [4], multilayer ceramic capacitors (MLCCs) [5], etc. Strontium titanate powders are also well known photocatalysts for $\mathrm{NO}_{\mathrm{x}}$ degradation under UV light. Both stoichiometric [6] and nonstoichiometric powders [7] have been shown to exhibit considerably higher photocatalytic activity than $\mathrm{P} 25 \mathrm{TiO}_{2}$ powder under the same illumination conditions. The nature of chemical bonding between $\mathrm{Sr}^{2+}, \mathrm{Ti}^{4+}$ and $\mathrm{O}^{2-}$ ions in $\mathrm{ABO}_{3}$ cubic perovskite structure leads to a unique structure which makes it a very interesting electronic material. Functional properties of $\mathrm{SrTiO}_{3}$ are strongly influenced by its crystal defects, particle size, morphology, etc., which ultimately depend on the preparation methods and conditions [8-10]. State-of-the-art application requires homogeneous micrograin ceramic materials with low impurity levels, smaller particle sizes and narrow size distribution, making alternative low-

\footnotetext{
* Corresponding author.

E-mail address: zivojinovic.jelena@gmail.com (J. Živojinović).
}

cost effective methods for large-scale production of phase-pure and nanosized $\mathrm{SrTiO}_{3}$ particles an important topic. While numerous methods for the production of $\mathrm{SrTiO}_{3}$ nanopowders such as sol-gel [11], hydrothermal [12], combustion [13], polymeric precursor [14], molten salt [15] and solvothermal [16] methods have been developed, $\mathrm{SrTiO}_{3}$ is dominantly obtained by conventional solid state reaction [17]. Most of these methods require high-purity chemicals, making them too expensive for industrial scale synthesis.

Sol-gel synthesis through alkoxide hydrolysis of strontium titanate powder produced, depending on synthesis conditions, particles of $350-800 \mathrm{~nm}$ in size. In addition, minor fraction of the sample contained ultra-fine particles $60 \mathrm{~nm}$ in size and agglomerates about $2 \mu \mathrm{m}$ in size [18]. Hydrothermal sol-gel method allows synthesis of relatively monodisperse $\mathrm{SrTiO}_{3}$ powder with nanoparticles in 40-100 nm range, using $\mathrm{TiCl}_{4}$ and $\mathrm{SrCl}_{2}$ as precursors, with reaction times of $12-48 \mathrm{~h}$ at $180{ }^{\circ} \mathrm{C}$, allowing limited size control and very homogeneous sample [19]. Another method to obtain ultra-fine powders involves combustion of a dehydrated form of a strontium-titanium precursor complex, resulting in single phase $\mathrm{SrTiO}_{3}$ nanoparticles $20-40 \mathrm{~nm}$ in size, produced in a singlestep combustion process [20]. On the other hand, in solid state 
reaction $\mathrm{SrTiO}_{3}$ powders were generally produced through mechanochemical reaction of strontium carbonate or strontium oxide with titanium dioxide powders at temperatures above $1000{ }^{\circ} \mathrm{C}$ $[21,22]$. These often have undesirable characteristics, such as large size, broad size distribution, hard agglomeration, phase impurities, etc. [9]. To the best of our knowledge, there have been no reports on mechanical activation of commercial strontium titanate powders to obtain nanoparticles less than $100 \mathrm{~nm}$ in size. There is a report of samples synthesized using a solid state reaction, followed by milling for $10-120 \mathrm{~min}$, resulting in particle sizes in $100-300 \mathrm{~nm}$ range [23].

In $\mathrm{SrTiO}_{3}$ thin films, it was observed that an increase in concentration of oxygen vacancies leads to an increase in lattice parameter a, without a change in the crystal structure even at relatively large concentrations of oxygen vacancies [24,25]. This increase can be correlated with strong Coulombic repulsion between strontium and titanium cations in the under stoichiometric phase and high vacancies concentrations can induce significant strain in the lattice, as much as $1-2 \%$, although no ordered arrangement of these vacancies, regardless of their concentration has ever been observed [26]. Under stoichiometric phases of strontium titanate exhibit a significant increase in electrical conductivity and semiconductor behavior compared to the insulating stoichiometric $\mathrm{SrTiO}_{3} . \mathrm{SrTiO}_{2.5}$ phase even exhibits metallic behavior at room temperature. Thermal stability of epitaxial SrTiO3 films shows that they are thermally stable up to around $550{ }^{\circ} \mathrm{C}$ in vacuum, where desorption of $\mathrm{SrO}$ occurs, followed by release of $\mathrm{SiO}$ and additional $\mathrm{SrO}$ around $850{ }^{\circ} \mathrm{C}$ [27].

Taking all of this into account, this work aims to investigate the influence of mechanical activation on the microstructural characteristics of $\mathrm{SrTiO}_{3}$ powder particles and the viability of mechanical activation as a method of production of high-purity $\mathrm{SrTiO}_{3}$ nanocrystalline powders.

\section{Experimental procedure}

$\mathrm{SrTiO}_{3}(99 \%$ purity, mean particle size $\leq 5 \mu \mathrm{m}$ ) powder was purchased from Aldrich (USA). Mechanical activation was conducted by ball-milling the samples of $6.5 \mathrm{~g}$ in $45-\mathrm{cm}^{3}$ tungsten carbide jar, with balls $5 \mathrm{~mm}$ in diameter (powder-to-ball ratio of $1: 20$ ), in a planetary micro mill (PULVERISETTE 7 premium line, FRITSCH). Mechanical activation was conducted for different time intervals (activation time): 0, 5, 10, 30, 60, 90 and $120 \mathrm{~min}$, in air. The samples are labeled as STO-0 to STO-120, according to the corresponding activation time.

Morphology and microstructure of non-activated and mechanically activated powders were analyzed by a Scanning Electron Microscope (SEM), Transmission Electron Microscope (TEM) and particle size analyzer. SEM measurements were conducted using JSM-6390 LV JEOL ( $25 \mathrm{kV}$ ), where sample tablets were crushed and covered with gold $(\mathrm{Au})$. TEM measurements were conducted using JEM-1400 $(120 \mathrm{kV})$, where samples were prepared through sonication of a $0.5 \%$ dispersion of dry powder samples in ethanol for 75 min deposition onto a carbon mesh. The particle size distribution (PSA) and the nature of the agglomerate were determined by a laser particle size analyzer (Mastersizer 2000, Malvern Instruments Ltd., UK). Samples were mixed with distilled water, and an aqueous suspension was obtained after 10-min ultrasonic disaggregation.

Nitrogen adsorption-desorption measurements were performed by a Sorptomatic 1990 Thermo Electron device at $-196{ }^{\circ} \mathrm{C}$. The samples were degassed at room temperature for $1 \mathrm{~h}$ under vacuum, and then heatedat $5{ }^{\circ} \mathrm{C} / \mathrm{min}$ to $110{ }^{\circ} \mathrm{C}$ and kept at this temperature for at least $18 \mathrm{~h}$. The obtained isotherms were analyzed using Advanced Data Processing v5.1 (Thermo Electron S. p. A.) software package, where $p$ and $p_{0}$ represented the equilibrium and saturation pressures of nitrogen at the adsorption temperature. Brunauer-Emmet-Teller (BET) method was applied for the determination of the specific surface area $\left(\mathrm{S}_{\mathrm{BET}}\right)$ of the samples, using the linear part of the nitrogen adsorption isotherms [28]. Mesopore volume was calculated according to the BarrettJoyner-Halenda method from the desorption branch of the isotherm [29].

The X-ray powder diffraction patterns were obtained using a Philips PW-150 diffractometer with $\mathrm{Cu}-\mathrm{K}_{\alpha}$ radiation, at room temperature, at angles $2 \theta$ of $10-90^{\circ}$ with a step of $0.05^{\circ}$ and retention time of $1 \mathrm{~s}$ per step. Rietveld analysis was performed with full refinement using GSAS II software package [30]. Obtained values of $\mathrm{R}_{\mathrm{wp}}$ (weighted residual factor) varied from $6.2 \%$ to $15.6 \%$ and the Goodness of Fit indicator was GoF 1.

Raman spectra were taken in the spectral range of 20-1200 $\mathrm{cm}^{-1}$ at room temperature, with a Horiba Jobin Yvon LabRam ARAMIS Raman system, using the $633 \mathrm{~nm}$ line of a He-Ne laser. Data was collected using a count time of $5 \mathrm{~s}$ with five averaging cycles. The samples were measured under a microscope using a $100 \times$ objective.

The diffuse reflectance UV-Vis spectra were recorded using a Nicolet Evolution 500 spectrometer with a diffuse reflectance accessory. The reflectance $(\mathrm{R})$ data were converted to pseudoabsorbance $f(R)$ using the Kubelka-Munk equation. The samples were grounded, heated overnight at $110^{\circ} \mathrm{C}$ and then scanned in the range of 200-800 nm using a SRS-99-010 Labsphere Spectralon white standard as reference material.

\section{Results and discussion}

Fig. 1 shows the results of SEM analysis of the powders after appropriate activation times (5, 10, 30, 60, 90 and $120 \mathrm{~min})$. Nonactivated $\mathrm{SrTiO}_{3}$ is a powder composed of predominantly polygonal particles $0.2-1.2 \mu \mathrm{m}$ in size with clear grain boundaries. After mechanical activation particle size decreased, depending on activation time, and was in the range between 70 and $390 \mathrm{~nm}$, with observable particle agglomeration. For longer activation times, more than $30 \mathrm{~min}$, activation induces stronger stress, causing the formation of a defect structure in a wider layer of powder particles and energy accumulation at the surface of powder particles. This was when formation of small grains was observed, occurring through dilation of grain boundaries within individual particles [31]. As a result of these processes, surface erosion and agglomeration was observed for the samples activated for $60 \mathrm{~min}$ and more. The agglomerates can be hard and soft, while the process of their formation is called secondary agglomeration [32]. Soft agglomerates are often formed in mechanically activated powders, and may have a negative impact on the sintering process aimed at obtaining ceramics with good performance. Continuous mechanical activation longer than 60 min leads to various forms of deformation, causing the strengthening or breaking of the agglomerates. Agglomerates fracture can be due to a fatigue failure mechanism and/ or due to the fragmentation of fragile agglomerates. In these samples, it can be observed that longer activation time of 90 min leads to dominant presence of secondary agglomerates, though particles remain constantly present. Mechanical activation for $120 \mathrm{~min}$ causes larger secondary agglomerates to break up into smaller agglomerates, while forming new ones at the same time. This is consistent with continuous deformation, cold welding and fracturing to yield a powder with a refined internal structure, but coarse and stable particle size [33].

Particles size analysis (PSA) shows the same effects observed in SEM (Fig. 2): mechanical activation led to the comminution of the initial powder particles, resulting in the shift of the distribution curve to smaller particle diameters, for powders activated for 5,10 


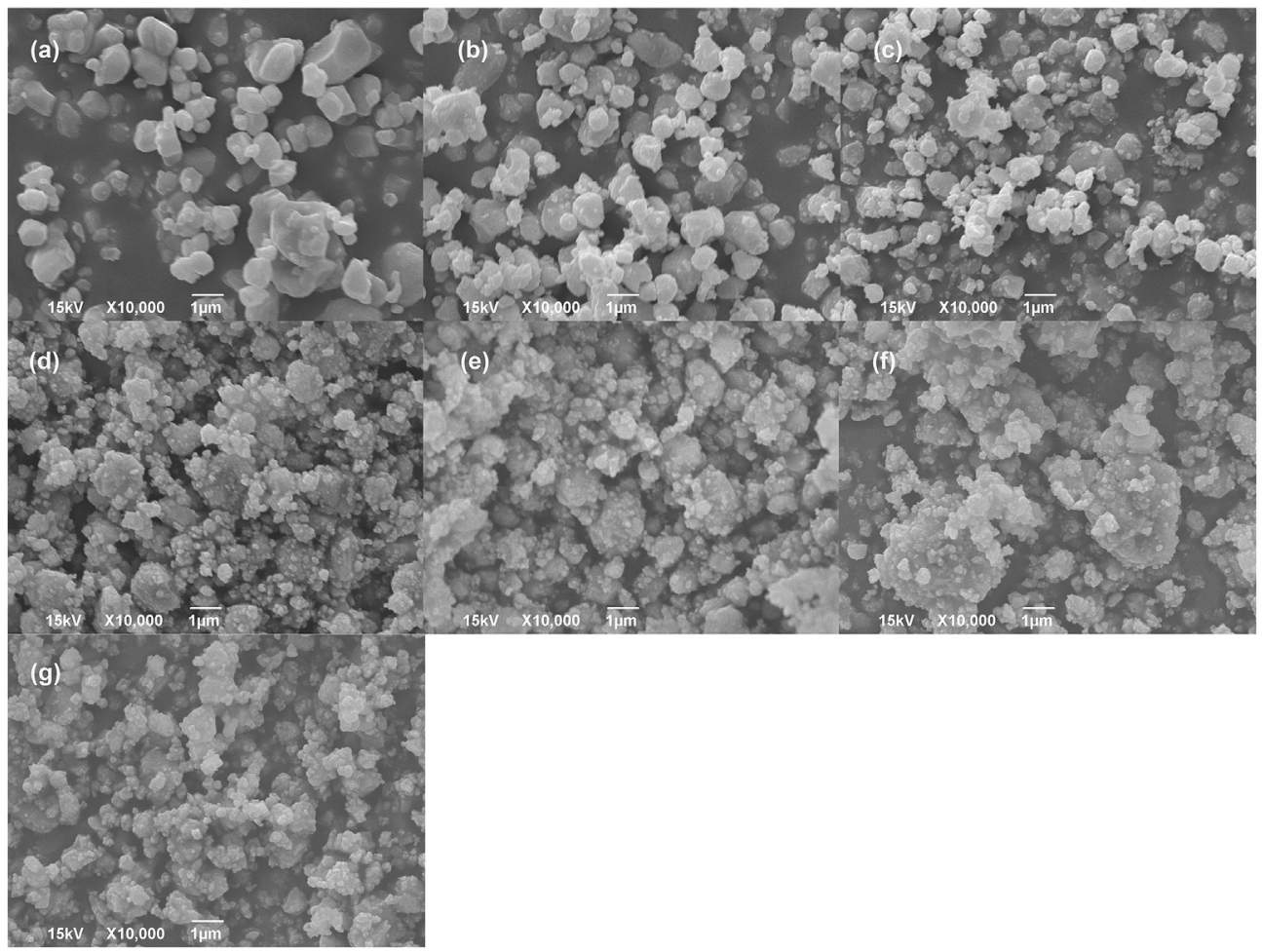

Fig. 1. SEM images of $\mathrm{SrTiO}_{3}$ powder: a) non-activated; and activated for: b) $5 \mathrm{~min}$, c) $10 \mathrm{~min} \mathrm{d)} 30 \mathrm{~min}$, e) $\left.60 \mathrm{~min}, \mathrm{f}\right) 90 \mathrm{~min}$, g) $120 \mathrm{~min}$.

and 30 min activation. Particle segregation in the initial powder sample can also be observed. Longer mechanical activation (for $60 \mathrm{~min}$ ) leads to agglomeration: agglomerates are approximately $15 \mu \mathrm{m}$ in size, while particles are $1.3 \mu \mathrm{m}$, resulting in bimodal size distribution observed in PSA. Further mechanical activation (for $90 \mathrm{~min}$ ) leads to comminution of these agglomerates to $2 \mu \mathrm{m}$ in size, with larger quantity in volume than that of particles, which are approximately $0.4 \mu \mathrm{m}$ in size. More intensive fragmentation of agglomerates is observed in samples mechanically activated for $120 \mathrm{~min}$, when the formation of new agglomerates occurs, as observed in SEM analysis (Fig. 1). Changes in median size with activation time are shown in Table 1. Ultimately, mechanical activation led to the comminution of the initial powder particles and a wider particle size distribution for powder activated for $120 \mathrm{~min}$.

TEM images show that the initial powder (Fig. 3a) consists of relatively large polygonal nanoparticles, hundreds of nanometers in diameter. Mechanical activation for 5 (Fig. 3b) and 10 (Fig. 3c) minutes causes comminution and breakage of these nanoparticles. After $30 \mathrm{~min}$ (Fig. 3d) agglomeration is observed and particle size is considerably reduced (from few tens to few hundreds of nanometers). Agglomerates increase in size after 60 (Fig. 3e) and $90 \mathrm{~min}$ (Fig. 3f), while after $120 \mathrm{~min}$ (Fig. 3g) there is, again, evidence of comminution and breakage, indicating that the agglomerates have undergone merging and sintering, only to be ground and broken again by the mechanical activation. This is all consistent with observation in SEM and PSA.

The adsorption/desorption isotherms of non-activated and mechanically activated samples were taken for a range $0<\mathrm{P} / \mathrm{P}_{0}<1$ (Fig. 4a). These isotherms correspond to type IV isotherm [34], which indicates the presence of mesopores $(2-50 \mathrm{~nm})$ in these samples, with a type $\mathrm{H}_{3}$ hysteresis loop in the range $0.18<\mathrm{P} / \mathrm{P}_{0}<1$. $\mathrm{H}_{3}$ hysteresis loop is associated with the presence of plate-like particles that form aggregates at high $\mathrm{P} / \mathrm{P}_{0}$. Fig. $3 \mathrm{~b}$ shows that mechanical activation causes a significant increase in pore volume of the $\mathrm{SrTiO}_{3}$ powder. Specific surface area $\left(\mathrm{S}_{\mathrm{BET}}\right)$ values were obtained by the BET method using the linear part of the adsorption isotherms for the interval $0.05<\mathrm{P} / \mathrm{P}_{0}<0.35$. Changes in the pore volume and specific surface area are shown in Fig. $4 \mathrm{~b}$. Nonactivated powder has a specific surface of $2.05 \mathrm{~m}^{2} \mathrm{~g}^{-1}$, and with activation, this increases up to $7.4 \mathrm{~m}^{2} \mathrm{~g}^{-1}$ for $60 \mathrm{~min}$ of activation. After further mechanical activation, the specific surface area remained relatively constant, which can be attributed to particle agglomeration due to an increase in the particle surface energy during comminution of the initial powder particles. Mesopore volume follows similar trend, and this can be attributed to the following: during mechanical activation of up to $60 \mathrm{~min}$, the dominant contribution to the increase in pore volume was formation of interparticle pores, due to formation of larger particles during secondary agglomeration; further mechanical activation leads to fragmentation of agglomerates and reduction in interparticle pores, resulting in a decrease in mesopore volume. Fig. $4 \mathrm{c}$ shows the pore size distribution of mesopores in non-activated and mechanically activated samples. The most frequent pore diameter in the non-activated sample is about $2 \mathrm{~nm}$, a value close to the limit for microporous materials ( $<2 \mathrm{~nm}$ ). Mechanical activation increases the average pore size and results in narrower pore size distribution.

Fig. 5 represents XRD patterns of the non-activated and activated $\mathrm{SrTiO}_{3}$ powders. XRD analysis indicates that the mechanical activation did not effect significant change in the cubic structure of the initial powder [JCPDS Card No. 89-4934 for $\mathrm{SrTiO}_{3}, 84-1778$ for $\mathrm{SrCO}_{3}, 89-4921$ for $\mathrm{TiO}_{2}$-a]. Diffraction patterns show sharp and intensive reflections for the initial powder, while increased activation times lead to an increase in peak broadening. This can be attributed to particle refinement, reduced crystallite size and generation of stress field associated with particle fragmentation and amorphization [35,36]. After 30 min of mechanical activation, new phases: orthorhombic strontium carbonate $\left(\mathrm{SrCO}_{3}\right)$ and tetragonal titanium dioxide $\left(\mathrm{TiO}_{2}\right)$, were observed, which can be attributed to 


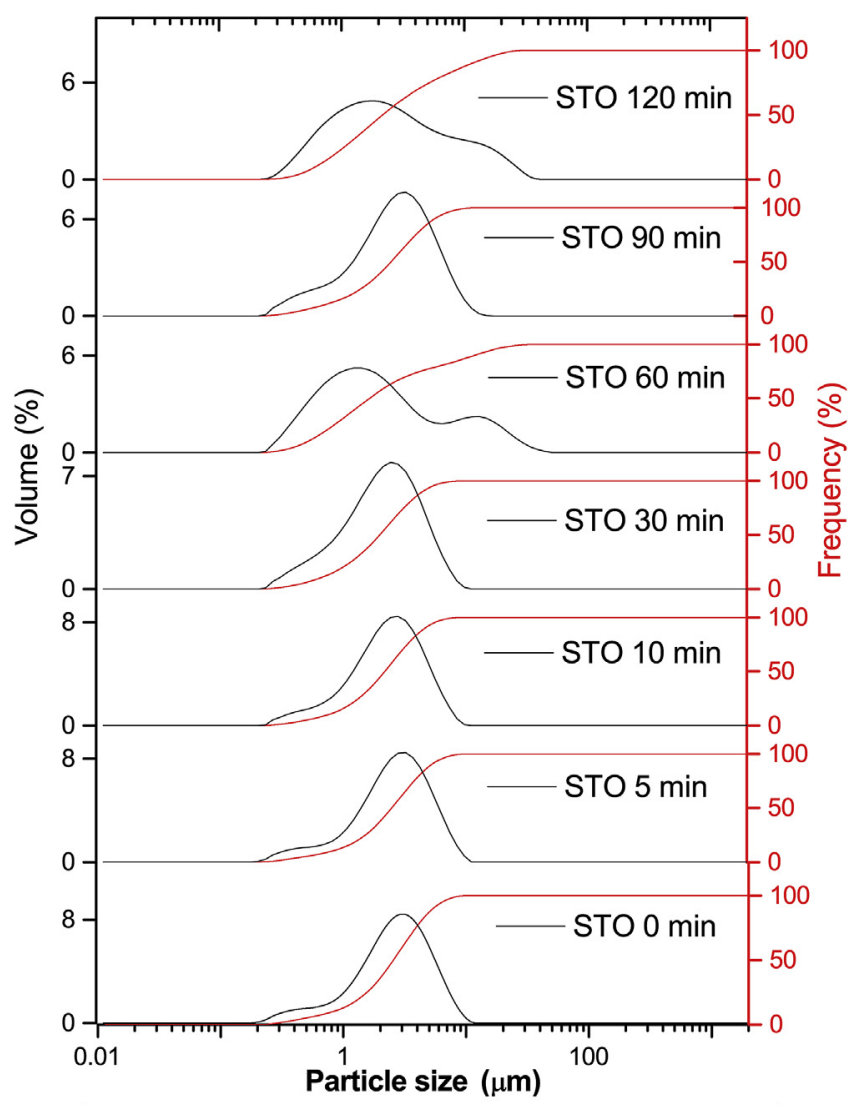

a reaction between the $\mathrm{SrTiO}_{3}$ powder and atmospheric $\mathrm{CO}_{2}$.

Mechanical activation is an intense process and leads to a significant increase in defects (vacancies, dislocations and unit cell volume). Lattice parameter $\mathrm{a}(=\mathrm{b}=\mathrm{c})$, percentage distribution of the $\mathrm{SrTiO}_{3}$, crystallite size and microstrain in mechanically activated samples were obtained using Rietveld refinement of XRD patterns (Table 1, Fig. 6).

At the beginning of the activation process, the dominant effects were attrition or erosion of the particle surface, which led to the crystallite size reduction during the first $10 \mathrm{~min}$ of mechanical activation, from $75 \mathrm{~nm}$ to $56 \mathrm{~nm}$, with an increase in lattice microstrain from $0.02 \%$ to $0.04 \%$. Increase in lattice parameter a suggests increase in the concentration of oxygen vacancies [24,25], while relatively minor increase in microstrain suggests that these vacancies are formed primarily on the surface, which is consistent with the process of mechanical activation. Due to relatively large crystallite size, the crystal lattice is able to accommodate surface defects without significant strain. After activation for $30 \mathrm{~min}$, crystallite size decreases to $34 \mathrm{~nm}$ and there is a sharp increase in microstrain to $0.14 \%$, coupled with a decrease in lattice parameter a. This is suggests that, due to smaller size, crystal structure of nanoparticles begins to strain, in order to compensate for the existence of surface defects and the increased surface free energy. Extension of the activation time to 60,90 and 120 min leads to the formation of agglomerates, in order to reduce the surface free energy, and crystallite sizes are in range from $34 \mathrm{~nm}$ to $20 \mathrm{~nm}$. The values of lattice strain vary from $0.09 \%$ to $0.26 \%$ with maximum of $0.26 \%$ for $90 \mathrm{~min}$ of activation for the particle size of $34 \mathrm{~nm}$. This suggests that mechanical activation for longer than 60 min caused sintering (as indicated by the increase in crystallite size after $90 \mathrm{~min}$ ), where, after $90 \mathrm{~min}$, the process is probably incomplete, resulting in higher concentration of oxygen vacancies and other defects, as indicated by the increase in lattice parameter a and microstrain. After $120 \mathrm{~min}$, these processes are most likely complete, resulting in stabilization of crystallites through size reduction, where less stable crystals or agglomerates are split into two or more smaller but more stable crystals. All of this is consistent with SEM and TEM measurements. It is significant that the microstrain in the final sample (after 120 min activation) is considerably lower than in any other sample activated for more than $10 \mathrm{~min}$, suggesting that prolonged activation likely lead to stabilization of particles through repetition of particle size reduction and grain sintering, resulting in a more stable sample, in spite its relatively small crystallite size. Therefore, applied mechanical activation can successfully lead to the formation of cubic nanocrystalline $\mathrm{SrTiO}_{3}$ powder with particle size of around $20 \mathrm{~nm}$.

Raman spectroscopy measurements were used to determine the lattice vibrational spectra of the $\mathrm{SrTiO}_{3}$ powders. It is well known that strontium titanate has an ideal cubic perovskite structure at room temperature with $P m 3 \mathrm{~m}$ space group and vibration modes $4 F_{1 u}+F_{2 u}$. One of the $F_{1 u}$ vibration modes is acoustic, while $F_{2 u}$ is an inactive ("silent") mode, resulting in 3 IR-active modes: $3 F_{1 u}$, which

Fig. 2. Particle size distribution of non-activated samples and samples mechanically activated for $5,10,30,60,90$ and $120 \mathrm{~min}$; volume cumulative frequencies shown below.

Table 1

Microstructural parameters of $\mathrm{SrTiO}_{3}$ obtained using Rietveld, PSA and BET analysis.

\begin{tabular}{|c|c|c|c|c|c|c|c|}
\hline \multirow{2}{*}{$\begin{array}{l}\text { Activation } \\
\text { time (min) }\end{array}$} & \multirow{2}{*}{$\begin{array}{l}\mathrm{SrTiO}_{3} \text { lattice } \\
\text { parameters }(\AA)\end{array}$} & \multicolumn{3}{|c|}{ Phase content (\%) } & \multirow{2}{*}{$\begin{array}{l}\text { Median particle } \\
\text { size }(\mu \mathrm{m})\end{array}$} & \multirow[t]{2}{*}{$S_{\text {BET }}\left(m^{2} g^{-1}\right)$} & \multirow[t]{2}{*}{$V_{\text {mes }}\left(\mathrm{cm}^{3} \mathrm{~g}^{-1}\right)$} \\
\hline & & $\mathrm{SrTiO}_{3}$ & $\mathrm{SrCO}_{3}$ & $\mathrm{TiO}_{2}$ & & & \\
\hline 0 & $3.9057 \pm 0.0001$ & 100 & 0 & 0 & 3.31 & 2.0471 & 0.0047 \\
\hline 5 & $3.9085 \pm 0.0001$ & 100 & 0 & 0 & 3.31 & 3.1335 & 0.0075 \\
\hline 10 & $3.9102 \pm 0.0001$ & 100 & 0 & 0 & 2.88 & 4.9739 & 0.0123 \\
\hline 30 & $3.9079 \pm 0.0001$ & $96 \pm 1$ & $3 \pm 1$ & $1 \pm 1$ & 2.51 & 7.1419 & 0.0207 \\
\hline 60 & $3.9066 \pm 0.0001$ & $95 \pm 1$ & $5 \pm 1$ & $1 \pm 1$ & 1.26 & 7.354 & 0.0228 \\
\hline 90 & $3.9085 \pm 0.0001$ & $92 \pm 1$ & $6 \pm 1$ & $2 \pm 1$ & 3.31 & 7.189 & 0.0226 \\
\hline 120 & $3.9067 \pm 0.0001$ & $92 \pm 1$ & $6 \pm 1$ & $2 \pm 1$ & 1.90 & 7.2104 & 0.0229 \\
\hline
\end{tabular}




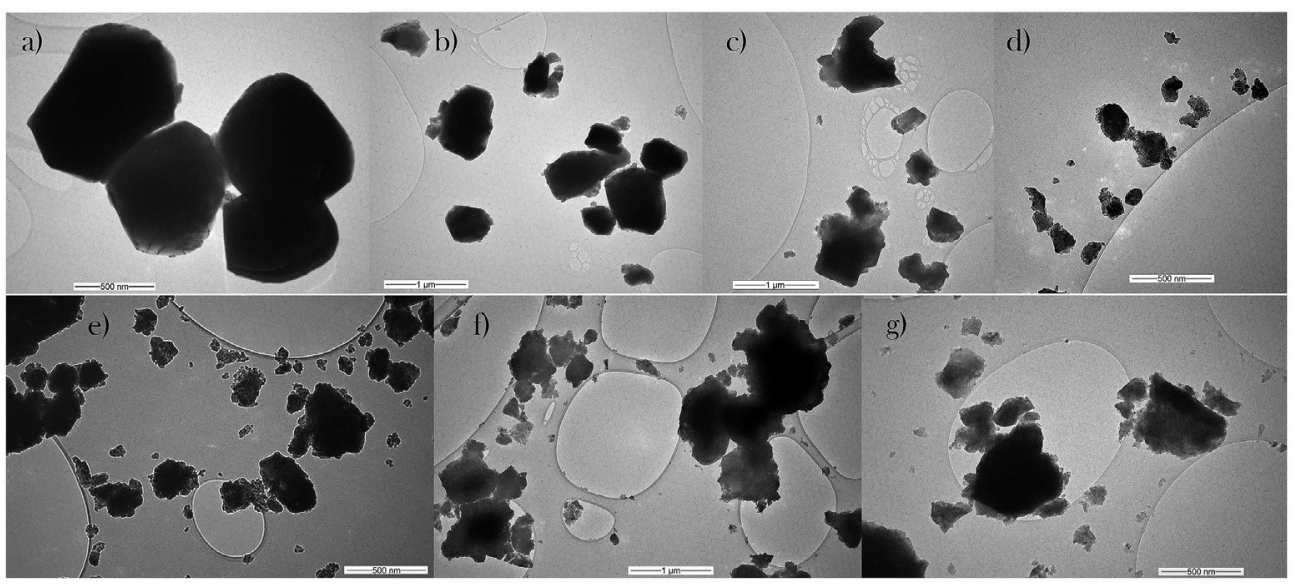

Fig. 3. TEM images of $\mathrm{SrTiO}_{3}$ powder: a) non-activated; and activated for: b) $5 \mathrm{~min}$, c) $10 \mathrm{~min}$ d) $30 \mathrm{~min}$, e) $\left.60 \mathrm{~min}, \mathrm{f}\right) 90 \mathrm{~min}$ g) $120 \mathrm{~min}$.
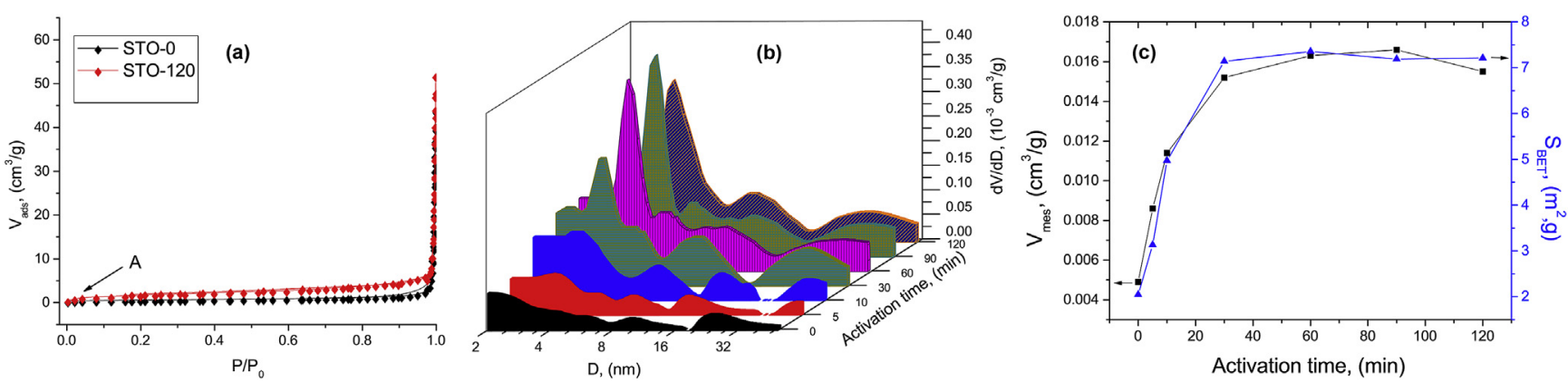

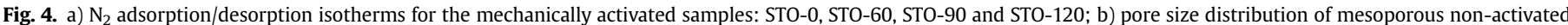
and mechanically activated powders: STO-5, STO-10, STO-30, STO-60, STO-90 and STO-120; c) mesopore volume and specific surface area as a function of activation time.

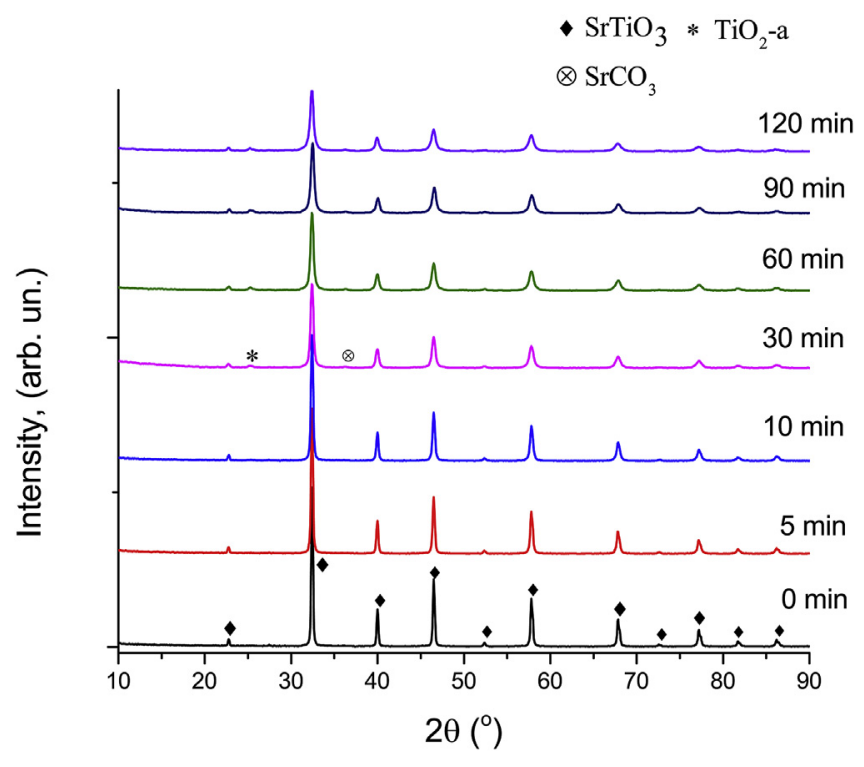

Fig. 5. XRD patterns of non-activated and activated $\mathrm{SrTiO}_{3}$ powders.

are Raman inactive. Therefore, no first-order Raman scattering is expected to occur in an ideal perovskite structure, instead, the Raman spectrum corresponds to the second-order scattering [37]. However, the presence of oxygen vacancies and other defects, strain effects or external electric field breaks the central symmetry of $\mathrm{SrTiO}_{3}$, resulting in the appearance of first-order modes in bulk

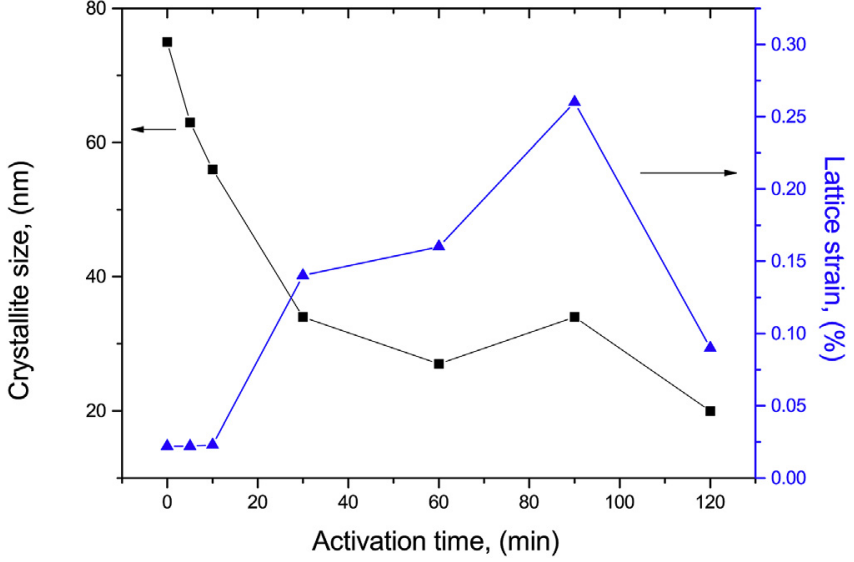

Fig. 6. Changes in crystallite size and lattice strain with activation time.

STO even at the $300 \mathrm{~K}[37,38]$.

Raman peaks of non-activated and mechanically activated powders were recorded in the range from $20 \mathrm{~cm}^{-1}$ to $1200 \mathrm{~cm}^{-1}$ (Fig. 7). In accordance with literature data, two very broad Raman effects from the second-order scattering were observed from $220 \mathrm{~cm}^{-1}$ to $500 \mathrm{~cm}^{-1}$ and $590 \mathrm{~cm}^{-1}$ to $760 \mathrm{~cm}^{-1}$, respectively [37]. Both of these consist of a large number of modes, typical of a roughgrained $\mathrm{SrTiO}_{3}$ powder, ceramics or film at $300 \mathrm{~K}$. The mode observed at $1026 \mathrm{~cm}^{-1}$ is also a second-order mode. Peaks observed at: $174 \mathrm{~cm}^{-1}, 540 \mathrm{~cm}^{-1}$ and $790 \mathrm{~cm}^{-1}$, in the non-activated 
powders, are assigned to following first-order modes: a doublet $\left(\mathrm{LO}_{1}+\mathrm{TO}_{2}\right)$, a $\mathrm{TO}_{4}$ mode and a $\left(\mathrm{LO}_{4}+\mathrm{A}_{2 \mathrm{~g}}\right)$ doublet, respectively $[39,40]$. $\left(E_{g}+B_{1 g}\right)$ peak at $152 \mathrm{~cm}^{-1}$, originating from R-point at the border of Brillouin zone, is barely noticeable. The origin of the modes at $\sim 107 \mathrm{~cm}^{-1}$ and at $\sim 126 \mathrm{~cm}^{-1}$ marked as $\mathrm{X}_{1}$ and $\mathrm{X}_{2}$ on the graph, is not entirely clear. Having in mind the analyses of other authors, $\mathrm{X}_{1}$ and $\mathrm{X}_{2}$, can be attributed to the existence of ferroelectric domains induced by defects in the crystal lattice [41], such as oxygen vacancies [42].

In the spectrum of the $\mathrm{SrTiO}_{3}$ powder activated up to $10 \mathrm{~min}$, slight changes can be observed: an increase in intensity of the $\left(\mathrm{LO}_{1}+\mathrm{TO}_{2}\right)$ peak which had a characteristic "Fano" shape, decrease and widening of the mode at $250 \mathrm{~cm}^{-1}$ and the amplification of the $\mathrm{TO}_{4}$ mode and $\mathrm{R}$-structural mode. The interference between the polar $\mathrm{TO}_{2}$ mode and the wide low-energy two-phonon continuum, caused by the polarization fluctuations in polar micro- or nanoregions usually induced by defects, and results in the Fano-shape of the $\left(\mathrm{LO}_{1}+\mathrm{TO}_{2}\right)$ peak $[38,43]$. The intensity of $\mathrm{TO}_{2}$ mode is proportional to the total volume of polar micro-regions. The appearance of $\mathrm{TO}_{2}$ phonons in $\mathrm{SrTiO}_{3}$ is usually accompanied by the appearance of remnant polarization [44]. A considerable increase in the intensity of the polar $\mathrm{TO}_{4}$ mode also indicates an increase in the

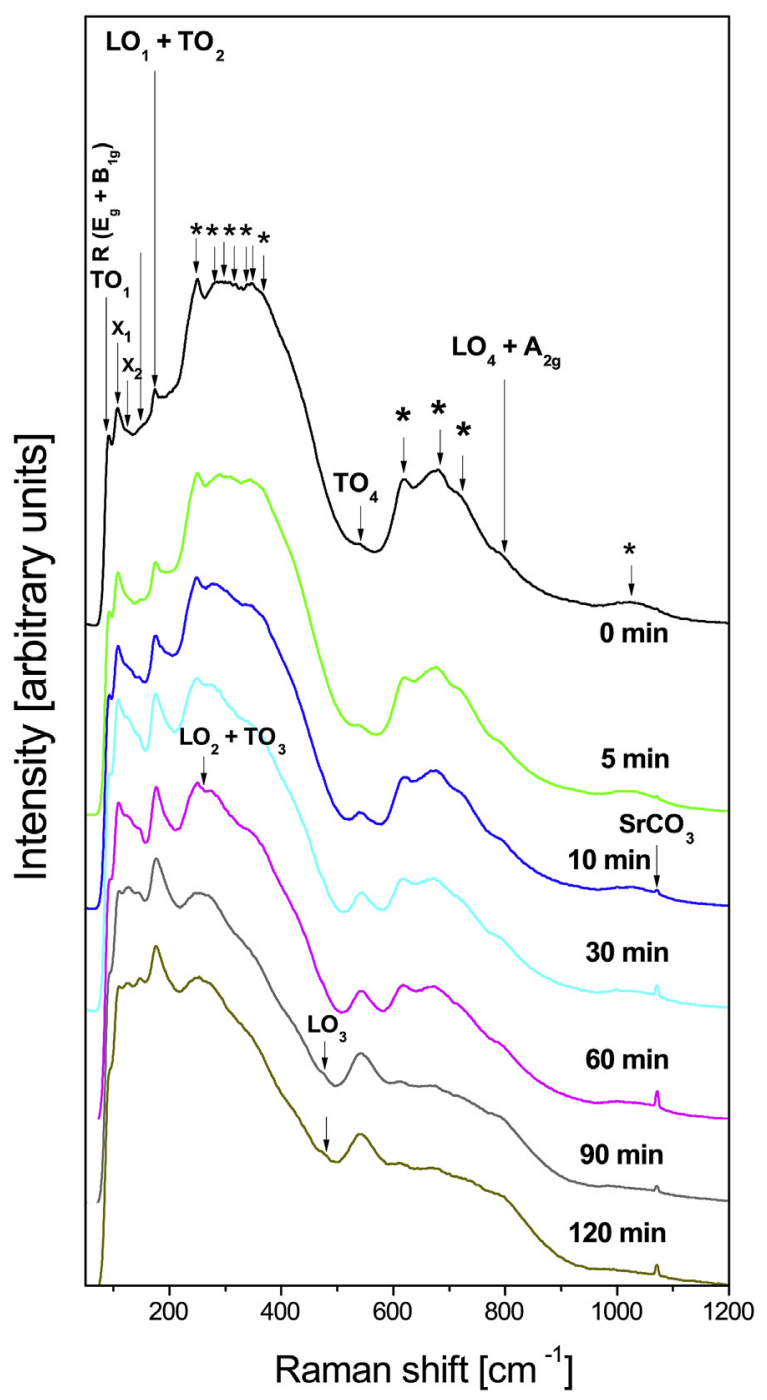

Fig. 7. The influence of the mechanical activation time on the Raman-spectra of $\mathrm{SrTiO}_{3}$ powders (assignment is described in detail in the text). volume of the local ferroelectric domains, which coexist with the dominant paraelectric phase [39].

The intensity of the entire Raman-effect in the range from $220 \mathrm{~cm}^{-1}$ to $400 \mathrm{~cm}^{-1}$ generally decreases with the further increase in activation time, which especially refers to the secondorder modes at higher wavenumbers. For the longest activations (90 and $120 \mathrm{~min}$ ), this wide Raman-effect becomes even lower than the $\left(\mathrm{LO}_{1}+\mathrm{TO}_{2}\right)$ peak, which is accompanied with a considerable decrease in the intensity of the second order Raman-mode in the range from 590 to $760 \mathrm{~cm}^{-1}$. On the other hand, the intensity of Rmode $\left(\mathrm{E}_{\mathrm{g}}+\mathrm{B}_{1 \mathrm{~g}}\right),\left(\mathrm{LO}_{1}+\mathrm{TO}_{2}\right)$ doublet and $\mathrm{TO}_{4}$ mode continuously increases. The rise in intensity of $\mathrm{X}_{1}$ and $\mathrm{X}_{2}$ modes can also be noticed, especially for activation up to $60 \mathrm{~min}$. Although the behavior of $\mathrm{X}_{1}$ and $\mathrm{X}_{2}$ modes at activation times up to $60 \mathrm{~min}$ is analogous to that of the $\mathrm{TO}_{2}$ (within the doublet $\mathrm{LO}_{1}+\mathrm{TO}_{2}$ ) and $\mathrm{TO}_{4}$ mode, their position does not suggest they can be assigned as firstorder fundamental Raman-modes, even though they can be linked to the disorder of the $\mathrm{SrTiO}_{3}$ lattice. Contribution of $\mathrm{LO}_{4}$ mode is also more evident for longer activation times, while the $\mathrm{LO}_{3}$ mode becomes noticeable only for activation over $60 \mathrm{~min}$. In the secondorder modes, for the activation time of $60 \mathrm{~min}$ a very weak silent doublet $\left(\mathrm{LO}_{2}+\mathrm{TO}_{3}\right)$ is observed at $\sim 258 \mathrm{~cm}^{-1}$, indicating the relaxation of the inversion symmetry in polycrystalline $\mathrm{SrTiO}_{3}$ [44] with increase in defect concentration and microstrain. Although the spectra of the sample activated for 120 min exhibits a slight increase of the silent peak, it still remains weak, indicating that there is no long-range structural distortion, as well as a small number of polar micro-regions and no overlap between the adjacent polar micro-regions [44].

Raman spectroscopy gave a clear evidence about the blue shift of the $\mathrm{TO}_{4}$ mode, $\mathrm{X}_{1}$ mode and $\left(\mathrm{LO}_{1}+\mathrm{TO}_{2}\right)$ doublet. The $\mathrm{X}_{1}$ mode shifts from $107 \mathrm{~cm}^{-1}$ to $109.8 \mathrm{~cm}^{-1}$. The doublet $\left(\mathrm{LO}_{1}+\mathrm{TO}_{2}\right)$ shifts from $174.2 \mathrm{~cm}^{-1}$ to $176.2 \mathrm{~cm}^{-1}$ for activation time up to 90 min and the analogue behavior is observed for the polar $\mathrm{TO}_{4}$ mode, which moves from $539.5 \mathrm{~cm}^{-1}$ to $542.7 \mathrm{~cm}^{-1}$ in the spectra of powders activated for $30-90 \mathrm{~min}$, and to $542 \mathrm{~cm}^{-1}$ in the sample activated for $120 \mathrm{~min}$. The observed shift of polar $\mathrm{TO}_{4}$ and $\mathrm{TO}_{2}$ modes is primarily caused by the introduction of microstrain into the $\mathrm{SrTiO}_{3}$ lattice, as well as by the reduction in crystallite size, while changes in intensity with increase of activation time are analogous to the reported change of their intensity with decrease in temperature [44]. Similar behavior of $\mathrm{TO}_{4}$ and $\mathrm{TO}_{2}$ modes, in both intensity and position are in accordance with the reported changes with the

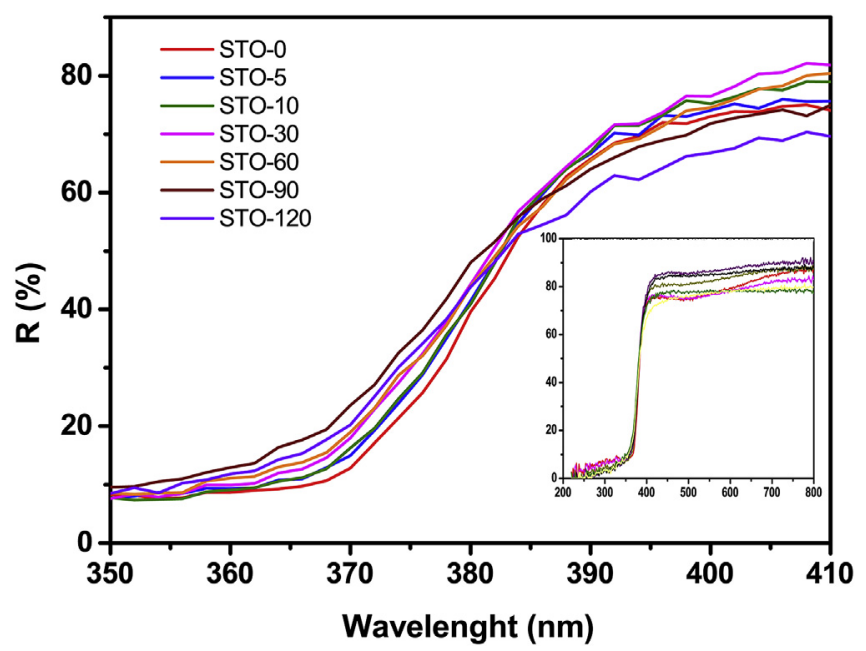

Fig. 8. UV-Vis diffuse reflectance spectra for $\mathrm{SrTiO}_{3}$ samples with different time of mechanical activation; inset: enlarged region of the onset of absorption. 

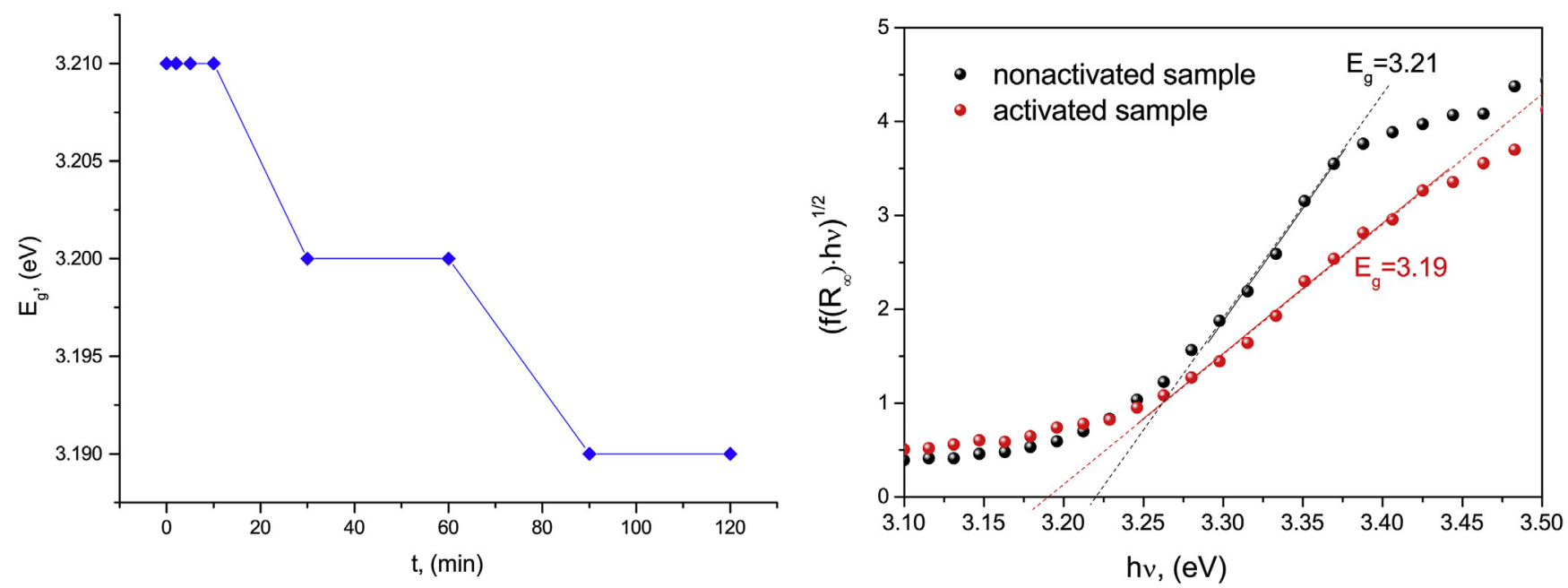

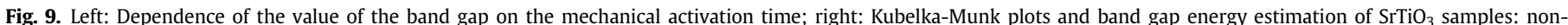
activated and mechanically activated in $120 \mathrm{~min}$.

decrease in particle size [45]. On the other hand, the R-structural mode exhibits a shift towards lower wavenumbers (red shift) with increase in activation time.

The occurrence of the strongest $\mathrm{SrCO}_{3}$ Raman line in activated powders (after $10 \mathrm{~min}$ ) and increase of its intensity with prolonged activation confirms the formation of surface $\mathrm{SrCO}_{3}$, also observed by XRD measurements, caused by the enhanced surface activity of activated powders and by the fact that the activation of powders was performed in air.

Optical properties of $\mathrm{SrTiO}_{3}$ non-activated and mechanically activated samples are investigated via Uv-VIS diffuse reflectance spectra, Fig. 8. Kubelka-Munk function is applied to convert the diffuse reflectance into the equivalent band gap energy.

$F\left(R_{\infty}\right)=\left(1-R_{\infty}\right)^{2} / 2 R_{\infty}=k / s$

here $R_{\infty}$ is the reflectance of the sample. Fig. 9. Shows the plot of $\left[\mathrm{F}\left(\mathrm{R}_{\infty} / h \nu\right]^{1 / 2}\right.$ vs. $h \nu$, in which linear segments are extended to intersect with the $h v$-axis to obtain the indirect band gap of the non-activated and mechanically activated samples for $120 \mathrm{~min}$. There is a small and gradual shift in the band gap, from 3.21 to $3.19 \mathrm{eV}$, as a consequence of mechanical activation, while the experimental value of the band gap for bulk strontium titanate is $3.21-3.25 \mathrm{eV}$ [46]. There are two possible sources of this shift: the increase in the amount of $\mathrm{TiO}_{2}$ with increase in the mechanical activation time, and the increase in oxygen vacancy concentration. $\mathrm{TiO}_{2}$ exhibits somewhat smaller band gap than $\mathrm{SrTiO}_{3}[47$ ] and its presence on the surface of the nanoparticles could lead to a gradual decrease in the overall band gap of the system. Also, ab initio calculations of vacancy defects in strontium titanate show that there is a slight decrease in the band gap with increase in oxygen vacancy concentration to 8.3\% [48]. Considering that the shift towards smaller band gap in our system occurs continuously with increase in activation time, while the changes in lattice parameters indicate fluctuations in the concentration of oxygen vacancies, there is considerably stronger correlation of the band gap shift with increase in $\mathrm{TiO}_{2}$ content than with increase in vacancy concentration.

\section{Conclusion}

Effect of mechanical activation on microstructural properties of $\mathrm{SrTiO}_{3}$ powders was investigated using a wide array of methods. It was observed that prolonged mechanical activation caused a decrease in average crystallite size from $75 \mathrm{~nm}$ to $20 \mathrm{~nm}$, and a corresponding increase in mesopore volume and specific surface area, with maximum $S_{\mathrm{BET}}=7.4 \mathrm{~m}^{2} / \mathrm{g}$. Other than the appearance of $\mathrm{SrCO}_{3}$ and $\mathrm{TiO}_{2}$ phases caused by the presence of air during mechanical activation, no other impurities originating either from the planetary micro mill or any other source have been observed in either XRD or Raman spectra, suggesting that this method preserves the chemical purity of the initial powder. Mechanical activation causes particle fragmentation, with an increased share of large diameter particles, due to secondary agglomeration during activation. The narrowest size distribution is observed in the powders mechanically activated for $30 \mathrm{~min}$, when aggregation of nanoparticles was first observed in SEM and TEM. Applied mechanical activation increased the intensity of all first-order Raman modes observed in the non-activated powders, and caused the appearance of new modes induced by defects and increased microstrain. The increase in intensity of $\left(\mathrm{LO}_{1}+\mathrm{TO}_{2}\right)$ doublet and $\mathrm{TO}_{4}$ mode indicated an increase in the total volume of polar microregions, i.e. an increase in the volume of local ferroelectric domains coexisting with the dominant paraelectric phase. Changes in the intensity of polar $\mathrm{TO}_{4}$ and $\mathrm{TO}_{2}$ modes with the increase in activation time is analogous to the reported changes in their intensity with temperature decrease. The observed shift in the position of polar TO modes to higher wavenumbers (blue shift) is mainly a consequence of the introduction of microstrain into the $\mathrm{SrTiO}_{3}$ powder, which increases from 0.02 to $0.26 \%$, as well as the consequence of a decrease in crystallite size. In contrast, markedly different behavior in terms of change in mode position was observed for the Rstructural mode. In addition, mechanical activation increases the volume of ferroelectric domains in $\mathrm{SrTiO}_{3}$ nanoparticles. UV-Vis measurements indicate that $\mathrm{TiO}_{2}$ contamination due to activation in air causes a slight shift in the band gap towards lower values.

\section{Acknowledgments}

This research was supported by the project OI 172057 of the Ministry of Education, Science and Technological Development of the Republic of Serbia.

\section{References}

[1] A.M. Schultz, T.D. Brown, M.P. Buric, S. Lee, K. Gerdes, P.R. Ohodnicki, High 
temperature fiber-optic evanescent wave hydrogen sensors using La-doped $\mathrm{SrTiO}_{3}$ for SOFC applications, Sens. Actuators B 221 (2015) 1307-1313.

[2] G.-L. He, Y.-H. Zhong, M.-J. Chen, X. Li, Y.-P. Fang, Y.-H. Xu, One-pot hydrothermal synthesis of $\mathrm{SrTiO}_{3}$-reduced graphene oxide composites with enhanced photocatalytic activity for hydrogen production, J. Mol. Catal. A Chem. 423 (2016) 70-76.

[3] F. Jing, D. Zhang, F. Li, J. Zhou, D. Sun, S. Ruan, High performance ultraviolet detector based on $\mathrm{SrTiO}_{3} / \mathrm{TiO}_{2}$ heterostructure fabricated by two steps in situ hydrothermal method, J. Alloys Compd. 650 (2015) 97-101.

[4] P. Jayabal, V. Sasirekha, J. Mayandi, K. Jeganathan, V. Ramakrishnan, A facile hydrothermal synthesis of $\mathrm{SrTiO}_{3}$ for dye sensitized solar cell application, J. Alloys Compd. 586 (2014) 456-461.

[5] K. Nishida, H. Kishi, H. Funakubo, H. Takeuchi, T. Katoda, T. Yamamoto, Evaluation of residual strain and oxygen vacancy in multilayer ceramic capacitor using laser Raman spectroscopy, Jpn. J. Appl. Phys. 46 (2007) 7005-7007.

[6] L. Chen, S. Zhang, L. Wang, D. Xue, S. Yin, Preparation and photocatalytic properties of strontium titanate powders via sol-gel process, J. Cryst. Growth 311 (2009) 746-748.

[7] U. Sulaeman, S. Yin, T. Sato, Solvothermal synthesis of designed nonstoichiometric strontium titanate for efficient visible-light photocatalysis, Appl. Phys. Lett. 97 (2010) 103102.

[8] H.-L. Li, Z.-N. Du, G.-L. Wang, Y.-C. Zhang, Low temperature molten salt synthesis of $\mathrm{SrTiO}_{3}$ submicron crystallites and nanocrystals in the eutectic $\mathrm{NaCl}-\mathrm{KCl}$, Mater. Lett. 64 (2010) 431-434.

[9] X. Liu, H. Bai, Liquid-solid reaction synthesis of $\mathrm{SrTiO}_{3}$ submicron-sized particles, Mater. Chem. Phys. 127 (2011) 21-23.

[10] T. Xian, H. Yang, J.F. Dai, Z.Q. Wei, J.Y. Ma, W.J. Weng, Photocatalytic properties of $\mathrm{SrTiO}_{3}$ nanoparticles prepared by a polyacrylamide gel route, Mater. Lett. 65 (2011) 3254-3257.

[11] K. Xu, M. Yao, J. Chen, P. Zou, Y. Peng, F. Li, X. Yao, Effect of crystallization on the band structure and photoelectric property of $\mathrm{SrTiO}_{3}$ sol-gel derived thin film, J. Alloys Compd. 653 (2015) 7-13.

[12] G. Wu, P. Li, D. Xu, B. Luo, Y. Hong, W. Shi, C. Liu, Hydrothermal synthesis and visible-light-driven photocatalytic degradation for tetracycline of Mn-doped $\mathrm{SrTiO}_{3}$ nanocubes, Appl. Surf. Sci. 333 (2015) 39-47.

[13] G. Saito, Y. Nakasugi, N. Sakaguchi, C. Zhu, T. Akiyama, Glycine-nitrate-based solution-combustion synthesis of $\mathrm{SrTiO}_{3}$, J. Alloys Compd. 652 (2015) 496-502.

[14] L.F. da Silvaa, L.J.Q. Maia, M.I.B. Bernardi, J.A. Andrés, V.R. Mastelaro, An improved method for preparation of $\mathrm{SrTiO}_{3}$ nanoparticles, Mater. Chem. Phys. 125 (2011) 168-173.

[15] T.X. Wang, S.Z. Liu, J. Chen, Molten salt synthesis of $\mathrm{SrTiO}_{3}$ nanocrystals using nanocrystalline $\mathrm{TiO}_{2}$ as a precursor, Powder Technol. 205 (2011) 289-291.

[16] J.-Q. Zheng, Y.-J. Zhu, J.-S. Xu, B.-Q. Lu, C. Qi, F. Chen, J. Wu, Microwaveassisted rapid synthesis and photocatalytic activity of mesoporous Nd-doped $\mathrm{SrTiO}_{3}$ nanospheres and nanoplates, Mater. Lett. 100 (2013) 62-65.

[17] H. Trabelsi, M. Bejar, E. Dhahri, M. Sajieddine, M.A. Valente, A. Zaoui, Effect of the oxygen deficiencies creation on the suppression of the diamagnetic behavior of $\mathrm{SrTiO}_{3}$ compound, J. Alloys Compd. 680 (2016) 560-564.

[18] A. Tkach, P.M. Vilarinho, M. Avdeev, A.L. Kholkin, J.L. Baptista, Synthesis by solgel and characterization of strontium titanate powder, Key Eng. Mater. 230-232 (2002) 40-43.

[19] S. Fuentes, R.A. Zarate, E. Chavez, P. Munoz, D. Diaz, D. Diaz- Droguett, P. Leyton, Preparation of $\mathrm{SrTiO}_{3}$ nanomaterial by a sol-gel-hydrothermalmethod, J. Mater. Sci. 45 (2010) 1448-1452.

[20] C.N. Georgea, J.K. Thomas, R. Josec, H. Padma Kumar, M.K. Suresh, V. Ratheesh Kumar, P.R. ShobanaWariar, J. Koshya, Synthesis and characterization of nanocrystalline strontium titanate through a modified combustion method and its sintering and dielectric properties, J. Alloys Compd. 486 (2009) $711-715$.

[21] V. Berbenni, A. Marini, G. Bruni, Effect of mechanical activation on the preparation of $\mathrm{SrTiO}_{3}$ and $\mathrm{Sr}_{2} \mathrm{TiO}_{4}$ ceramics from the solid state system $\mathrm{SrCO}_{3}-\mathrm{TiO}_{2}$, J. Alloys Compd. 329 (2001) 230-238.

[22] M. Makarova, A. Dejneka, J. Franc, J. Drahokoupil, L. Jastrabik, V. Trepakov, Soft chemistry preparation methods and properties of strontium titanate nanoparticles, Opt. Mater 32 (2010) 803-806.

[23] B. Psiuk, J. Szade, R. Wrzalik, M. Osadnik, T. Wala, Milling-induced phenomena in $\mathrm{SrTiO}_{3}$, Ceram. Int. 40 (2014) 6957-6961.

[24] M. Hiratani, Y. Tarutani, T. Fukazawa, M. Okamoto, K. Takagi, Growth of SrTiO3 thin films by pulsed-laser deposition, Thin Solid Films 227 (1993) 100-104.
[25] M. Hiratani, K. Imagawa, K. Takagi, Orientation and crystal structure of SrTiO3 thin films prepared by pulsed laser deposition, Jpn. J. Appl. Phys. Part 34 (1) (1995) 254-260.

[26] R. Perez-Casero, J. Perrière, A. Gutierrez-Llorente, D. Defourneau, E. Millon, W. Seiler, L. Soriano, Thin films of oxygen-deficient perovskite phases by pulsed-laser ablation of strontium titanate, Phys. Rev. B 75 (2007) 165317.

[27] L.V. Goncharova, D.G. Starodub, E. Garfunkel, T. Gustafsson, V. Vaithyanathan J. Lettieri, D.G. Schlom, Interface structure and thermal stability of epitaxial SrTiO3 thin films on Si (001), J. Appl. Phys. 100 (2006) 014912.

[28] Y. Wang, H. Xu, X. Wang, X. Zhang, H. Jia, L. Zhang, J. Qiu, A general approach to porous crystalline $\mathrm{TiO}_{2}, \mathrm{SrTiO}_{3}$, and $\mathrm{BaTiO}_{3}$ spheres, J. Phys. Chem. B 110 (2006) 13835-13840.

[29] X. Yang, C. Li, R. Fu, Nitrogen-enriched carbon with extremely high mesoporosity and tunable mesopore size for high-performance supercapacitors, J. Power Sources 319 (2016) 66-72.

[30] B.H. Toby, R.B. Von Dreele, GSAS-II: the genesis of a modern open-source all purpose crystallography software package, J. Appl. Crystallogr. 46 (2013) 544-549.

[31] H.-J. Fecht, Nanostructure formation by mechanical attrition, NanoStruct. Mater. 6 (1995) 33-42.

[32] A. Peleš, V.P. Pavlović, S. Filipović, N. Obradović, L. Mančić, J. Krstić, M. Mitrić B. Vlahović, G. Rašić, D. Kosanović, V.B. Pavlović, Structural investigation of mechanically activated ZnO powder, J. Alloys Compd. 648 (2015) 971-979.

[33] C. Suryanarayana, Mechanical alloying and milling, Pro. Mater. Sci. 46 (2001), $1-184$.

[34] S. Shahabuddin, N.M. Sarih, S. Mohamad, J.J. Ching, $\mathrm{SrTiO}_{3}$ nanocube-doped polyaniline nanocomposites with enhanced photocatalytic degradation of methylene blue under visible light, Polymer 8 (2016) 27.

[35] Y. Hu, O.K. Tan, J.S. Pan, X. Yao, A new form of nanosized $\mathrm{SrTiO}_{3}$ material for near-human-body temperature oxygen sensing applications, J. Phys. Chem. B 108 (2004) 11214-11218.

[36] V.P. Pavlović, J. Krstić, M.J. Šćepanović, J. Dojčilović, D.M. Minić, J. Blanuša, S. Stefanović, V. Mitić, V.B. Pavlović, Structural investigation of mechanically activated nanocrystalline $\mathrm{BaTiO}_{3}$ powders, Ceram. Int. 37 (2011) 2513-2518.

[37] S. Banerjee, D.I. Kim, R.D. Robinson, S.S. Wong, I. Herman, Observation of Fano asymmetry in Raman spectra of $\mathrm{SrTiO}_{3}$ and related perovskite nanocubes Appl. Phys. Lett. 89 (2006) 223130.

[38] A. Tkach, P.M. Vilarinho, A.L. Kholkin, A. Pashkin, S. Veljko, J. Petzelt, Broadband dielectric spectroscopy analysis of relaxational dynamics in Mn-doped SrTiO3 ceramics, Phys. Rev. B 73 (2006) 104113.

[39] A.B. Shi, W.Z. Shen, H. Wu, Phase transition temperature of $\mathrm{SrTiO}_{3}$ ultrathin films: an annealing study by ultraviolet Raman spectroscopy, Appl. Phys. Lett. 91 (2007) 112910.

[40] T. Ostapchuk, J. Petzelt, V. Zelezny, A. Pashkin, J. Pokorny, I. Drbohlav, R. Kuzel D. Rafaja, B.P. Gorshunov, M. Dressel, Ch. Ohly, S. Hoffmann-Eifert, R. Waser Origin of soft-mode stiffening and reduced dielectric response in $\mathrm{SrTiO}_{3}$ thin films, Phys. Rev. B 66 (2002) 235406.

[41] P. Ranson, R. Ouillon, J.-P. Pinan-Lucarre, Ph. Pruzan, S.K. Mishra, R. Ranjan, D. Pandey, The various phases of the system $\mathrm{Sr}_{1-\mathrm{x}} \mathrm{Ca}_{\mathrm{x}} \mathrm{TiO}_{3}$ : a Raman scattering study, J. Raman Spectrosc. 36 (2005) 898-911.

[42] D.A. Tenne, I.E. Gonenli, A. Soukiassian, D.G. Schlom, S.M. Nakhmanson, K.M. Rabe, X.X. Xi, Raman study of oxygen reduced and re-oxidized strontium titanate, Phys. Rev. B 76 (2007) 024303.

[43] A.A. Sirenko, I.A. Akimov, J.R. Fox, A.M. Clark, H.C. Li, W. Si, X.X. Xi, Observation of the first-order Raman scattering in the $\mathrm{SrTiO}_{3}$ thin films, Phys. Rev. Lett. 82 (1999) 4500-4503.

[44] Y.L. Du, G. Chen, M.S. Zhang, Investigation of structural phase transition in polycrystalline $\mathrm{SrTiO}_{3}$ thin films by Raman spectroscopy, Solid State Commun. 130 (2004) 577.

[45] X.W. Wu, D.J. Wu, X.J. Liu, Negative pressure effects in $\mathrm{SrTiO}_{3}$ nanoparticles investigated by Raman spectroscopy, Solid State Commun. 145 (2008) $225-258$.

[46] N. Bickel, G. Schmidt, K. Heinz, K. Müller, Ferroelectric relaxation of the SrTiO3(100) surface, Phys. Rev. Lett. 62 (1989) 2009.

[47] D.O. Scanlon, C.W. Dunnill, J. Buckeridge, S.A. Shevlin, A.J. Logsdail, S.M. Woodley, C. Richard, A. Catlow, M.J. Powell, R.G. Palgrave, I.P. Parkin, G.W. Watson, T.W. Keal, P. Sherwood, A. Walsh, A.A. Sokol, Band alignment of rutile and anatase $\mathrm{TiO}_{2}$, Nat. Mater. Lett. 12 (2013) 798-801.

[48] M. Djermouni, A. Zaoui, S. Kacimi, B. Bouhafs, Vacancy defects in strontium titanate: ab initio calculation, Comput. Mater. Sci. 49 (2010) 904-909. 